\title{
Microstructural differences in the reinforcement of a gastropod shell against predation
}

\author{
Renee Avery, Ron J. Etter* \\ Biology Department, University of Massachusetts, 100 Morrissey Boulevard, Boston, Massachusetts 02125, USA
}

\begin{abstract}
Gastropod shells are important antipredator structures that vary morphologically in response to predation risk, often increasing in thickness when the risk of predation is greater. Because the shell is composed of different microstructures that vary in energetic cost and strength, shell thickness may be increased in different ways. We tested whether the common intertidal snail Nucella lapillus differs in microstructure between shores with different predation risk, and whether any differences in microstructure affect shell strength. Predation risk varies with degree of wave exposure, so we compared shell microstructure and strength between snails from different exposure regimes. $N$. lapillus shells are made of a strong but energetically expensive crossed lamellar microstructure and a weaker but less energetically expensive homogeneous microstructure. Independent of exposure regime, the homogeneous microstructure was used to thicken the shell as snails increase in size. The thickness of the stronger crossed-lamellar microstructure changes little with snail size or predator risk. Whelks from wave-protected shores, where predation risk is high, have much thicker shells than conspecifics from exposed shores, where predation risk is low. The greater thickness is largely due to a disproportionate increase in the thickness of the homogeneous layer, and this increase translates into a much stronger shell. The advantage of using the weaker microstructure may lie in the fact that it is energetically cheaper and can be deposited more quickly, allowing snails to grow more rapidly to a size refuge. Reinforcing the shell with weaker and energetically cheaper materials that allow rapid growth to a size refuge may be a more important strategy for reducing the risk of predation than simply maximizing strength.
\end{abstract}

KEY WORDS: Nucella lapillus $\cdot$ Shell strength $\cdot$ Microstructure $\cdot$ Predation $\cdot$ Wave action

\section{INTRODUCTION}

Shells protect the soft anatomy of gastropods from abiotic and biotic stresses, and vary dramatically within species in response to spatial and temporal environmental variation (Vermeij 1978). Molluscan shells evolved initially during the Paleozoic, probably as antipredator structures in response to the diversification of highly efficient and mobile metazoan predators. Both structure and composition determine how effective a shell is in reducing predation. Under intense predation, snails typically have thick shell walls and apertural lips (Ebling et al. 1964, Bertness \& Cunningham 1981, Currey \& Hughes 1982, Vermeij 1982, Brandwood 1985, Palmer 1985, Seeley 1986,
West et al. 1991, Trussell 1996, West \& Cohen 1996, Boulding et al. 1999), occasionally with occluding teeth (Hughes \& Elner 1979, Appleton \& Palmer 1988), reduced apertures (Vermeij 1978, Hughes \& Elner 1979, Trussell et al. 1993), as well as increased shell sculpture and short spires (Vermeij 1978, Palmer 1979). Each of these features reduces the efficacy of shell-crushing predators.

Shell strength can also be influenced by its microstructure, since the ability to resist breaking forces varies among microstructural types (Vermeij \& Currey 1980, Currey 1988). Shells can be reinforced against predation by altering their orientation, composition, or number of microstructural layers (Currey \& Kohn 1976, West \& Cohen 1996). In addition to differences in 
strength, some microstructures are more energetically expensive to produce (Palmer 1983) or are more dense (Taylor \& Layman 1972), which in turn influences the costs of production and transport. As a consequence, natural selection must balance the costs and benefits of alternate microstructural elements. Across gradients where selective pressures and energy availability are changing, selection may favor shells with different microstructures.

In the intertidal zone, dramatic gradients in predation (Menge 1978, Palmer 1979, Bertness et al. 1981, Seeley 1986), energy availability (Brown \& Quinn 1988, Etter 1989), desiccation (Etter 1988a), thermal stress (Etter 1988b) and hydrodynamic forces (Denny et al. 1985, Denny 1988, 1999) exist along shores differentially exposed to wave energy, and these gradients profoundly affect snail morphology (reviewed in Trussell \& Etter 2001). Morphological changes along wave-exposure gradients probably represent adaptive responses to the direct and indirect effects of the hydrodynamic forces imposed by breaking waves (reviewed in Denny 1988, 1999). Because both predation intensity and energy availability vary, wave-swept environments represent an interesting setting for testing how microstructure might respond to changing selective pressures.

Nucella lapillus is a common intertidal snail in the North Atlantic that exhibits considerable morphological variation. Whelks from wave-protected shores are larger, with thicker shells, than conspecifics from wave-swept shores (Kitching et al. 1966, Currey \& Hughes 1982). The larger size and thicker shells reflect selective (Hughes \& Elner 1979, Palmer 1979, Vermeij 1982) and plastic (Appelton \& Palmer 1988, Palmer 1990, Trussell \& Nicklin 2002) responses to greater predation pressure and food availability (Etter 1989) on protected shores. Although snails on protected shores have thicker shells, and this reduces their vulnerability to crushing predators, nothing is known about how shell microstructure responds to wave exposure. We tested whether $N$. lapillus differ in shell microstructure among shores of different wave exposure and, if so, whether such differences affect shell strength.

Gastropod shells are composed of 1 or more layers of crystals of calcium carbonate, with each crystal surrounded by a glycoprotein organic matrix. Calcium carbonate is deposited as aragonite or calcite crystals whose conformation determines the microstructure of the shell (see Bøggild 1930, Watabe 1988, Bandel 1990). Both mechanical properties and shell microstructure vary among species (Taylor \& Layman 1972, Currey \& Taylor 1974, Currey 1976, 1980, 1988, Currey \& Kohn 1976, Wainwright et al. 1976). The shell produced by $N$. lapillus has 2 microstructural types - an inner crossed-lamellar layer and an outer homogeneous layer (Fig. 1).

A crossed-lamellar structure is the most widely used microstructure throughout the Mollusca and is often compared mechanically to nacre. It is inferior to nacre in tension and crushing strength (Taylor \& Layman 1972, Currey \& Taylor 1974, Currey 1976), but is strong, with a high nominal fracture toughness (Currey \& Kohn 1976, Jackson et al. 1988, 1990, Kuhn-Spearing et al. 1996, Kamat et al. 2000). Crossed-lamellar microstructure is composed of lathes offset by approximately $90^{\circ}$ between layers (Currey \& Kohn 1976) and is often refered to as ceramic plywood. A crack traveling through one layer moves easily until it encounters a change in lathe orientation. Without additional energy to break across the lathes, a change in crack direction occurs. Upon changing direction, the crack loses energy and dissipates (Currey \& Kohn 1976). Currey (1977) likened the fracture to the Cook-Gordon mechanism. As a crack approaches the junction between 2 lathes, the lathes will tend to separate because of the tensile stresses that are present parallel to and just ahead of the crack. This dissipates energy and retards crack propagation (Cook \& Gordon 1964). However, a crossed-lamellar structure has a greater organic content than a homogeneous one, with relatively more complex geometrical construction (Wainwright et al. 1976, Currey 1988), making it energetically expensive to produce. Shell regeneration rates are inversely proportional to organic content (Palmer 1983) suggesting that organic frameworks for crystal formation are energetically expensive.

Homogeneous microstructure is typically regarded as mechanically inferior to other types of microstruc-

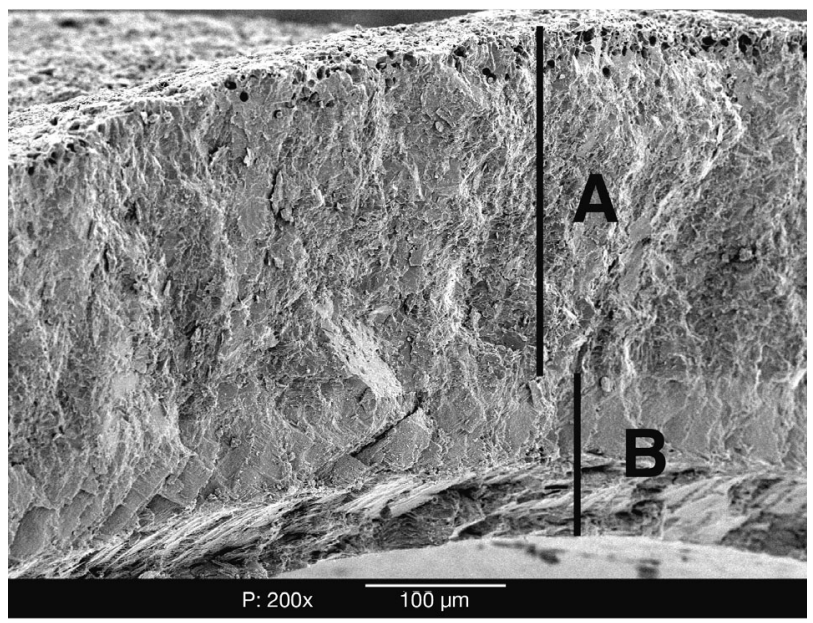

Fig. 1. Nucella lapillus. Scanning electron micrograph of the shell microstructure (200x), showing (A) outer layer of shell consisting of homogeneous material and (B) inner layer consisting of crossed-lamellar material. There are 2 distinct layers of crossed-lamellar material oriented in different planes 
ture (Currey 1980). Isodiametric, aragonite crystals yield a simple architecture with low organic matrix surrounding the crystals (Taylor \& Layman 1972, Wainwright et al. 1976, Currey 1980). The low organic content and simple architecture allows it to be produced more quickly than other microstructures (Currey 1988), but provide little protection from crack propagation. A crack traveling through the isodiametric blocks deviates little from its path because no structural boundaries interfere (Currey 1980), although the crystals might cause the energy of a crack to dissipate around them, potentially slowing the crack. Although mechanically inferior to other microstructures (Currey 1988), homogeneous microstructure may increase resistance to abrasion and attack by borers (Gabriel 1981) and may comprise an inexpensive way of increasing overall thickness. Materials that are weaker and cheaper to produce (e.g. homogeneous) may be favored over stronger more expensive structures (e.g. crossed-lamellar) under certain environmental conditions.

Nucella lapillus shells vary in thickness among shores of different wave action, largely in response to concomitant changes in predation pressure. Because the shell is composed of 2 layers that differ biomechanically and energetically, an increase in thickness can be achieved by (1) both microstructural layers increasing proportionately, (2) a disproportionate increase in the weaker but less expensive layer (e.g. homogeneous structure), or (3) a disproportionate increase in the stronger, but more expensive layer (e.g. crossedlamellar structure). The second strategy might be favored when energy is limited or where rapid growth is needed. The third might be advantageous when energy is abundant and predation intense.

\section{MATERIALS AND METHODS}

Study sites and shell collection. We identified 3 pairs of wave-exposed and wave-protected shores in the Gulf of Maine from Boston, Massachusetts, USA, to approximately $1 \mathrm{~km}$ north of the Maine border (Fig. 2) from US Geographical Survey maps. Exposed sites were selected from headlands with eastern facing shores because the most powerful waves in New England waters typically originate from the NE and waves tend to focus on headlands due to topographic steering (Denny 1988). Exposed sites also had steeper sloping shores, allowing more wave energy from ocean swells to impact the shoreline. Protected sites were within sheltered bays or inlets and were partially enclosed by a physical barrier such as an island, pier or breakwater that dramatically reduced wave action.

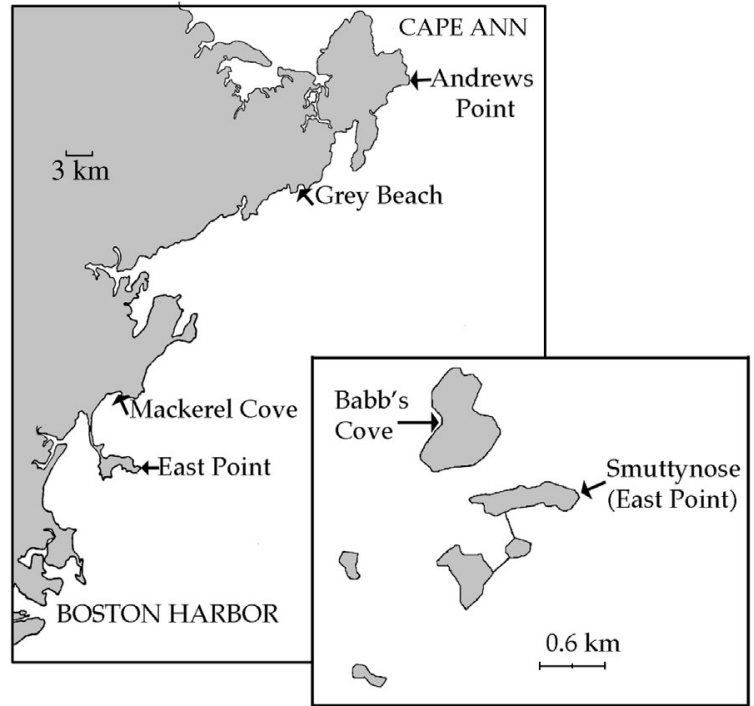

Fig. 2. Location of study sites along northern Massachusetts coast and Isles of Shoals (inset) which lie further north, approximately $11 \mathrm{~km}$ east of coastal border between New Hampshire and Maine. The 3 exposed sites are East Point, Nahant, Massachusetts; Andrews Point, Rockport, Massachusetts; and East Point, Smuttynose Island, Maine; the 3 protected sites are Mackerel Cove, Beverly, Massachusetts; Grey Beach, Magnolia, Maine; and Babb's Cove, Appledore Island, Maine. (See first subsection of 'Materials and methods' for detailed site descriptions)

The southernmost sites were East Point (EP), Nahant, Massachusetts $\left(42^{\circ} 25^{\prime} 50^{\prime \prime} \mathrm{N}, 70^{\circ} 55^{\prime} \mathrm{W}\right)$ for exposed and Mackerel Cove (MC), Beverly, Massachusetts $\left(42^{\circ} 32^{\prime} 50^{\prime \prime} \mathrm{N}, 70^{\circ} 52^{\prime} 30^{\prime \prime} \mathrm{W}\right)$, for protected shores. East Point consists of relatively steep granitic slopes that drop into the subtidal zone. The upper intertidal zone was covered with dense mats of Semibalanus balanoides and the mid to lower intertidal zone with dense beds of Mytilus edulis and the short form of Fucus vesiculosus. Mackerel Cove is $16 \mathrm{~km}$ north of EP and has a south facing, gradually sloping shore with an off-shore sand bar that significantly reduces wave energy. The substrate includes granite outcrops and boulders surrounded by sandy beach interspersed with loose pebbles. The boulders in the mid to lower intertidal are covered with barnacles, with mussels interspersed among the boulders. Sparse, short forms of $F$. vesiculosus and Ascophyllum nodosum occurred in the lower intertidal and in areas of standing water. Wave action at these 2 sites was measured previously (Etter 1988a) using wave-force dynamometers (Palumbi 1984). Maximum wave forces differed dramatically between EP and MC with wave energies 2 to 3 times greater at EP.

The central pair of exposed and protected sites were Andrews Point (AP), Rockport, Massachusetts $\left(42^{\circ} 40^{\prime} 58^{\prime \prime} \mathrm{N}, 70^{\circ} 37^{\prime} 50^{\prime \prime} \mathrm{W}\right)$ and Grey Beach (GB), 
Magnolia, Massachusetts $\left(42^{\circ} 34^{\prime} 35^{\prime \prime} \mathrm{N}, 72^{\circ} 44^{\prime} 39^{\prime \prime} \mathrm{W}\right)$, respectively. GB lies approximately $15 \mathrm{~km}$ north of $\mathrm{MC}$ and is protected by a breakwater and Kettle Island. It has a very gradual slope of dense boulders that tapers to a sandy beach interspersed with few boulders. A dense blanket of Fucus vesiculosus and Ascophyllum nodosum along with many ephemeral algal species covered the intertidal boulders. Rock surfaces were covered with large Semibalanus balanoides with Mytilus edulis at the base of the algae. Andrews Point is $15 \mathrm{~km}$ north of GB and has horizontal rocky shelves with nearly smooth surfaces. The intertidal zone slopes gradually to the subtidal and then drops off quickly. Mats of $S$. balanoides were abundant in cracks or edges of the shelves in the high intertidal areas, while $M$. edulis were more prevalent deeper in cracks and at mid-intertidal. In the low zone there was a thick carpet of short form $F$. vesiculosus and Chondrus crispus.

The northernmost exposed and protected sites were East Point, Smuttynose Island (SN), Maine $\left(42^{\circ} 60^{\prime} 45^{\prime \prime} \mathrm{N}, 70^{\circ} 35^{\prime} 44^{\prime \prime} \mathrm{W}\right)$ and Babb's Cove (BC), Appledore Island, Maine $\left(42^{\circ} 41^{\prime} 0^{\prime \prime} \mathrm{N}, 70^{\circ} 37^{\prime} 0^{\prime \prime} \mathrm{W}\right)$, respectively. The eastern point of Smuttynose Island is the most exposed site at the Isles of Shoals. The shore has broad step-like horizontal and vertical surfaces. The horizontal surfaces were covered with Semibalanus balanoides while Mytilus edulis were found in cracks and closer to the edges. Sparse, short forms of Fucus vesiculosus occurred at the easternmost edge facing the waves. Babb's Cove is a western facing shore and is protected by Babb's Rock. The surface is primarily boulders that are loosely piled creating small 'caverns' beneath. At the end of the piled rocks are remnants of pilings from a former pier. The rocks are completely covered with long blades of Ascophyllum nodosum and Fucus vesiculosus, and these are covered with many ephemeral algal species.

Approximately 20 to 40 Nucella lapillus were randomly collected from each site at mid to low tide levels. Snail size ranges differed significantly between shores of differing wave energy, with few small snails $(<15 \mathrm{~mm})$ present on protected shores and mostly small snails on exposed shores (Etter 1989). To obtain similar size ranges from all sites, we actively searched for and collected small individuals on protected shores. Unusually large snails from the protected sites were excluded from the analysis because such large snails did not occur on exposed shores, and ANCOVA is most successful when overlap in the covariate is maximized (Huitema 1980). If populations do not overlap strongly in the covariate, comparisons of slopes or elevations (least-square adjusted means) involves assuming linearity and extrapolating outside the range of observed values, which may be invalid.
Shell preparation and morphological measurements. Snails were lightly boiled to remove soft body tissues, and the shell was dried at room temperature. Shell length, from the apex to the tip of the siphonal canal, was measured to the nearest $0.05 \mathrm{~mm}$ using Vernier calipers.

The force required to break a shell was quantified by placing the shells aperture-side down between 2 horizontal metal plates. The top plate was lowered until it touched the shell and then pressure was applied to the shell by lowering the plate further at a rate of $1 \mathrm{~mm} \mathrm{~s}^{-1}$. The lower plate was pressure sensitive and connected to a computer to measure the amount of force on the shell. When a shell failed (i.e. broke or cracked), the force required was recorded as shell load in Newtons. We excluded 6 shells from GB because the force required to break them exceeded the measurement capacity of the crushing apparatus ( $>531.39 \mathrm{~N})$.

Shell thickness and microstructure measurements. Light microscopy was used to measure shell thickness and the thickness of the microstructural layers. To test whether a light microscope could be used to accurately measure microstructure, we compared the results to measurements taken with a scanning electron microscope (SEM).

Shell fragments of 15 snails from East Point and 6 from Mackerel Cove were collected after the crushing procedure and prepared for the SEM. Only fragments from the center of the aperture lip were used. Specimens were sputter-coated with $50 \AA(5 \mathrm{~nm})$ of gold in a Hummer X sputter-coater and observed under a JEOL JSM 5200 SEM. The edges of the fragments were photographed and digitally scanned.

To prepare fragments for light microscopy, they were embedded in epoxy and shaved with a diamond saw to obtain a cross-section perpendicular to the aperture lip and to the long axis of the shell. This cross-section allows consistent and accurate measurement of shell thickness and the thickness of the microstructural layers. The cross-section was polished with a $0.05 \mathrm{~mm}$ aluminum oxide polishing agent. A digital imaging system attached to a light microscope was used to record images of the shell cross-sections.

Shell thickness and microstructure layer thickness were measured and calibrated to the nearest $0.01 \mu \mathrm{m}$ from both SEM and light microscope images. All measurements were taken within the shell wall just dorsal to the shell tooth on the aperture edge, because the tooth is often enlarged in shells from protected shores. Total shell thickness was measured by taking the average of 20 measurements made at a right angle to the inner edge of the shell (A and B in Fig. 1). The crossedlamellar structure (the inner shell layer) was measured in the same manner (B in Fig. 1). Thickness of the homogeneous layer (the outer shell layer) was calcu- 
lated by subtracting the inner layer thickness from the total thickness of the shell.

To determine if the 2 techniques provided similar estimates, we regressed measures from the light microscope against those from the SEM. The slope of the line for total shell thickness was 1.00 and the $\mathrm{r}^{2}$ value was 0.94 , indicating that both techniques provided essentially the same results. For the crossedlamellar layer the slope was 0.92 with an $\mathrm{r}^{2}$ value of 0.93, while for the homogeneous layer the slope was 1.01 with an $\mathrm{r}^{2}$ value of 0.94 . Because both techniques provided similar estimates, we used the simpler, less expensive, light microscope to quantify microstructure, as described above.

Statistical analyses. Shell load, shell thickness and microstructural characteristics were compared among shores differentially exposed to wave action using a nested ANCOVA. We used both shell length and shell thickness as covariates to test how microstructure and strength vary among snails from different exposure regimes at similar size and thickness. The factors were site nested within exposure (i.e. EP, AP and $\mathrm{SN}$ were nested within the exposed shore factor, and $\mathrm{MC}, \mathrm{GB}$ and $\mathrm{BC}$ were nested within the protected shore factor). If the exposure main effect was significant but slopes were heterogeneous, we used a Johnson-Neyman test (Huitema 1980) to identify the range of covariates over which populations were different. All analyses used $\log _{10}$ transformed data and regression equations were computed using least-squares linear regression. Because the covariates were measured with error, we also calculated slopes for the reduced major axis (RMA; LaBarbera 1989).

\section{RESULTS}

Shell thickness increased with increasing shell length at all sites (Fig. 3, Table 1), but the thickness of the 2 microstructural layers did not increase at the same rate. Crossed-lamellar thickness showed no consistent change with snail size in 4 of the 6 populations (Table 2). The only significant regressions for the crossed-lamellar layer were for populations SN and $\mathrm{BC}$, which had slopes similar to those for the homogeneous layer (the 95\% confidence intervals overlapped), although in both cases the RMA were greater for the crossed-lamellar layer. Homogeneous layer thickness increased with increasing shell size in all populations (Table 2), and the increase was generally faster than for the crossed-lamellar layer. The difference in rates is obvious when we compare the relative thickness of each microstructural layer to overall shell thickness (Fig. 4). The faster increase in the thickness of the homogeneous layer indicates that, as snails

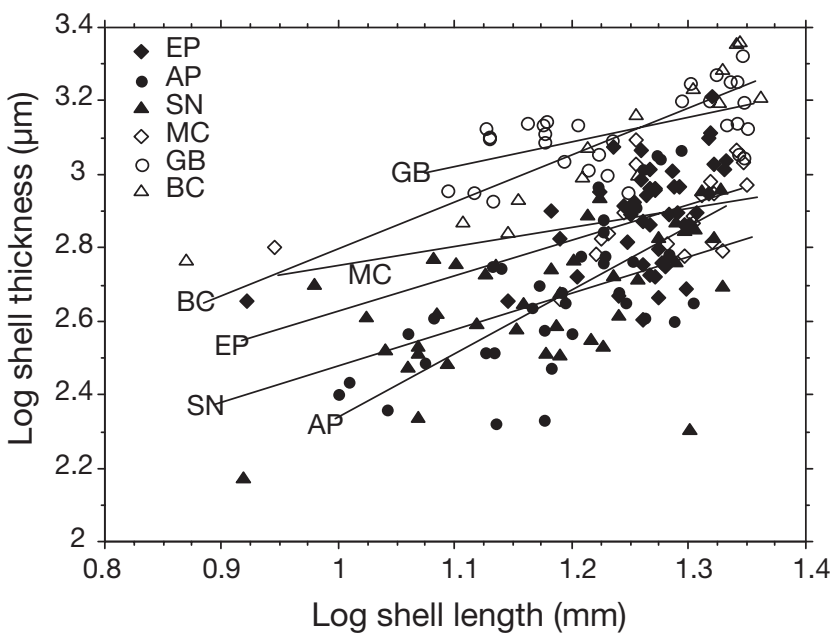

Fig. 3. Nucella lapillus. Shell thickness as a function of shell length for snails from different exposure regimes. Filled symbols: wave-exposed shores; open symbols: wave-protected shores. Full site names and regression lines are given in Table 2

grow, the greater thickness is achieved by disproportionately increasing the less expensive microstructural layer.

\section{Exposed versus protected shores}

When controlled for differences in shell length, shell thickness and the thickness of the homogeneous layer were much greater for snails from protected shores (Table 1, Fig. 5). Surprisingly, thickness of the crossedlamellar layer did not differ between exposure regimes. Similar sized snails produce shells with similar crossed-lamellar layer thickness, but because overall thickness of the shell is much less on exposed shores, the crossed-lamellar microstructure makes up a larger fraction of the shell. Snail shells from protected shores are considerably thicker than those from exposed shores, and this enhanced thickness reflects an increase in the thickness of the less energetically expensive homogeneous layer. The interaction for homogeneous layer indicates modest heterogeneity of slopes, although a Johnson-Neyman test (Huitema 1980) indicated that elevations were greater for snails from sheltered shores.

The relationship changed when we compared microstructural composition at similar thickness (use shell thickness as covariate) (Table 1, Fig. 6). Although the thickness of the homogeneous layer was still larger for protected shore snails, the crossedlamellar layer was thinner. The interaction for crossed-lamellar layer thickness suggests modest heterogeneity of slopes, but a Johnson-Neyman test 
Table 1. Nucella lapillus. Results of nested analysis of covariance (ANCOVA) testing for differences in shell thickness, microstructure thickness and load between exposed and protected snails (Exposure). Covariates are either shell length or shell thickness. All variables were log transformed

\begin{tabular}{|c|c|c|c|c|}
\hline Source & df & SS & F-ratio & p-value \\
\hline \multicolumn{5}{|l|}{ Shell thickness vs. shell length } \\
\hline Exposure & 1 & 2.216 & 136.629 & $<0.0001$ \\
\hline Shore[Exposure] & 4 & 0.994 & 15.329 & $<0.0001$ \\
\hline Log Shell Length[Exposure] & 2 & 1.511 & 46.575 & $<0.0001$ \\
\hline Log Shell Length $\times$ Shore[Exposure] & 4 & 0.154 & 2.387 & 0.0528 \\
\hline \multicolumn{5}{|l|}{ Homogeneous layer thickness vs. shell length } \\
\hline Exposure & 1 & 3.001 & 153.569 & $<0.0001$ \\
\hline Shore[Exposure] & 4 & 1.268 & 16.227 & $<0.0001$ \\
\hline Log Shell Length[Exposure] & 2 & 1.626 & 41.609 & $<0.0001$ \\
\hline Log Shell Length $\times$ Shore[Exposure] & 4 & 0.202 & 2.594 & 0.0382 \\
\hline \multicolumn{5}{|c|}{ Crossed-lamellar layer thickness vs. shell length } \\
\hline Exposure & 1 & 0.087 & 2.218 & 0.1382 \\
\hline Shore[Exposure] & 4 & 0.906 & 5.739 & 0.0002 \\
\hline Log Shell Length[Exposure] & 2 & 0.629 & 7.972 & 0.0005 \\
\hline Log Shell Length $\times$ Shore[Exposure] & 4 & 0.241 & 1.530 & 0.1953 \\
\hline \multicolumn{5}{|c|}{ Homogeneous layer thickness vs. shell thickness } \\
\hline Exposure & 1 & 0.014 & 16.079 & $<0.0001$ \\
\hline Shore[Exposure] & 4 & 0.014 & 4.013 & 0.0039 \\
\hline Log Shell Thickness [Exposure] & 2 & 4.918 & 2737.207 & $<0.0001$ \\
\hline Log Shell Thickness $\times$ Shore[Exposure] & 4 & 0.003 & 0.839 & 0.5016 \\
\hline \multicolumn{5}{|c|}{ Crossed-lamellar layer thickness vs. shell thickness } \\
\hline Exposure & 1 & 0.664 & 19.989 & $<0.0001$ \\
\hline Shore[Exposure] & 4 & 0.567 & 4.264 & 0.0026 \\
\hline Log Shell Thickness [Exposure] & 2 & 1.798 & 27.035 & $<0.0001$ \\
\hline Log Shell Thickness $\times$ Shore[Exposure] & 4 & 0.384 & 2.890 & 0.0238 \\
\hline \multicolumn{5}{|l|}{ Load vs. shell length } \\
\hline Exposure & 1 & 2.297 & 131.224 & $<0.0001$ \\
\hline Shore[Exposure] & 4 & 7.693 & 109.857 & $<0.0001$ \\
\hline Log Shell Length[Exposure] & 2 & 1.534 & 43.835 & $<0.0001$ \\
\hline Log Shell Length $\times$ Shore[Exposure] & 4 & 0.055 & 0.795 & 0.5294 \\
\hline \multicolumn{5}{|l|}{ Load vs. shell thickness } \\
\hline Exposure & 1 & 0.067 & 4.437 & 0.0366 \\
\hline Shore[Exposure] & 4 & 4.451 & 73.038 & $<0.0001$ \\
\hline Log Shell Thickness [Exposure] & 2 & 1.969 & 64.633 & $<0.0001$ \\
\hline Log Shell Thickness $\times$ Shore[Exposure] & 4 & 0.068 & 1.119 & 0.3488 \\
\hline
\end{tabular}

quently, when controlled for shell thickness, snails from exposed shores should be less vulnerable to breakage.

\section{Shell strength}

The strength of the shell increased with increasing size (Fig. 7), and largely reflected the increase in thickness. At a similar size, shells from protected shore populations required a much greater force to fracture compared to conspecifics from more waveswept environments (Table 1, Fig. 8). The difference in strength largely reflected the difference in shell thickness between exposed and protected shells of similar size. If we control for shell thickness, protected shore snails still required a greater force to fracture than did conspecifics from exposed shores, but the difference was less (Table 1, Fig. 8). Most variation was among shores; despite the heterogeneity among shores within exposure regimes, shells from sheltered environments were stronger at similar thickness, and this difference in strength of shells of the same thickness was surprising, since shells from exposed shores had a greater proportion of the stronger crossed-lamellar microstructure.

Because shell strength is likely to be influenced simultaneously by both shell length and thickness, we also tested whether shells of exposed and sheltered snails differed in strength, after controlling for both covariates. Snails from protected shores still required a greater (Huitema 1980) indicated elevations were greater for snails from exposed shores over most of the range of shell thickness. Only 1 regression line (MC) differed in slope from the 3 exposed-shore lines (Tukey multiple comparison, $\mathrm{p}<0.05)$. The Johnson-Neyman test indicated that larger snails (>1000 $\mu \mathrm{m}$ shell thickness) from MC did not differ from snails on the 3 exposed shores in crossed lamellar layer thickness. However, this needs to be interpreted carefully because few snails from the exposed shore reach this thickness, so the power to detect a difference is limited. On average, the ANCOVA suggests that at similar shell thickness (but very different shell size), exposed shore snails use proportionately more of the stronger crossed lamellar layer to build the shell. Conse- force to fracture the shell (ANCOVA $p=0.0013$ ) when both shell length and thickness were used as covariates.

\section{DISCUSSION}

To a large extent, Nucella lapillus shell strength reflects its thickness and, independent of exposure regime, snails disproportionately increase the thickness of the homogeneous layer with increasing size. Snails from different exposure regimes, and thus different predator risk environments, produce shells that differ in microstructure, and this translates into differences in shell strength. On protected shores, where the risk of predation is high and food widely available 
Table 2. Nucella lapillus. Least-squares linear regression lines for shell thickness, microstructure thickness and load as a function of shell length for each population. Slopes are given with \pm 1 SE. RMA: slope for reduced major axis calculated for significant regressions. EP: East Point; AP: Andrews Point; SN: Smuttynose Island; BC: Babb's Cove; GB: Grey Beach; MC: Mackerel Cove (full size descriptions in first subsection of 'Materials and methods')

\begin{tabular}{|c|c|c|c|c|c|c|}
\hline Site & Equation & $\mathrm{R}^{2}$ & $\mathrm{df}$ & F-ratio & $\mathrm{p}$-value & RMA \\
\hline \multicolumn{7}{|c|}{ Log shell thickness $(y)$ vs. log shell length $(x)$} \\
\hline EP & $y=1.65+0.98( \pm 0.30) x$ & 0.200 & 1,43 & 10.78 & 0.002 & 2.19 \\
\hline $\mathrm{AP}$ & $y=0.68+1.68( \pm 0.37) x$ & 0.456 & 1,35 & 29.37 & $<0.0001$ & 2.49 \\
\hline SN & $y=1.50+0.98( \pm 0.22) x$ & 0.336 & 1,39 & 19.74 & $<0.0001$ & 1.69 \\
\hline $\mathrm{BC}$ & $y=1.49+1.30( \pm 0.20) x$ & 0.778 & 1,12 & 42.13 & $<0.0001$ & 1.47 \\
\hline GB & $y=2.29+0.67( \pm 0.18) x$ & 0.331 & 1,29 & 14.32 & 0.0007 & 1.16 \\
\hline $\mathrm{MC}$ & $y=2.25+0.51( \pm 0.27) x$ & 0.161 & 1,18 & 3.45 & 0.08 & \\
\hline \multicolumn{7}{|c|}{ Log homogeneous layer thickness $(y)$ vs. log shell length $(x)$} \\
\hline EP & $y=1.53+1.03( \pm 0.33) x$ & 0.181 & 1,43 & 9.52 & 0.0035 & 2.42 \\
\hline AP & $y=0.44+1.82( \pm 0.34) x$ & 0.452 & 1,35 & 28.91 & $<0.0001$ & 2.71 \\
\hline SN & $y=1.48+0.92( \pm 0.25) x$ & 0.253 & 1,39 & 13.20 & 0.0008 & 1.83 \\
\hline $\mathrm{BC}$ & $y=1.41+1.33( \pm 0.20) x$ & 0.779 & 1,12 & 42.35 & $<0.0001$ & 1.51 \\
\hline GB & $y=2.24+0.68( \pm 0.19) x$ & 0.315 & 1,29 & 13.35 & 0.001 & 1.21 \\
\hline $\mathrm{MC}$ & $y=2.14+0.56( \pm 0.25) x$ & 0.223 & 1,18 & 5.17 & 0.035 & 1.19 \\
\hline \multicolumn{7}{|c|}{ Log crossed-lamellar layer thickness $(y)$ vs. log shell length $(x)$} \\
\hline EP & $y=1.43+0.39( \pm 0.45) x$ & 0.017 & 1,43 & $0.75^{\circ}$ & 0.39 & \\
\hline $\mathrm{AP}$ & $y=0.90+0.78( \pm 0.39) x$ & 0.103 & 1,35 & 4.01 & 0.053 & \\
\hline SN & $y=0.44+1.27( \pm 0.27) x$ & 0.363 & 1,39 & 22.25 & $<0.0001$ & 2.11 \\
\hline $\mathrm{BC}$ & $y=0.65+1.11( \pm 0.44) x$ & 0.350 & 1,12 & 6.47 & 0.026 & 1.88 \\
\hline GB & $y=1.47+0.32( \pm 0.38) x$ & 0.023 & 1,29 & 0.68 & 0.41 & \\
\hline $\mathrm{MC}$ & $y=1.76-0.02( \pm 0.70) x$ & $3.7 \mathrm{E}-5$ & 1,18 & 0.0007 & 0.98 & \\
\hline \multicolumn{7}{|c|}{ Log shell load $(y)$ vs. log shell length $(x)$} \\
\hline EP & $y=1.25+0.41( \pm 0.42) x$ & 0.021 & 1,43 & 0.95 & 0.3345 & \\
\hline AP & $y=1.29+0.69( \pm 0.15) x$ & 0.362 & 1,35 & 19.89 & $<0.0001$ & 1.15 \\
\hline SN & $y=1.36+0.67( \pm 0.09) x$ & 0.564 & 1,39 & 50.57 & $<0.0001$ & 0.89 \\
\hline $\mathrm{BC}$ & $y=0.24+1.73( \pm 0.26) x$ & 0.791 & 1,12 & 45.67 & $<0.0001$ & 1.94 \\
\hline GB & $y=1.19+1.11( \pm 0.22) x$ & 0.461 & 1,29 & 24.89 & $<0.0001$ & 1.63 \\
\hline $\mathrm{MC}$ & $y=0.01+1.57( \pm 0.54) x$ & 0.322 & 1,18 & 8.55 & 0.0091 & 2.77 \\
\hline
\end{tabular}

of nacre sandwiched between 2 layers of prismatic material (Currey 1980), 2 microstructure types that are mechanically comparable to crossed-lamellar and homogeneous layers, respectively. Currey (1980) suggests that this arrangement is adaptive, because prisms can be deposited quickly providing a protective scaffold for the slower deposition of the stronger, nacreous material. A similar argument can be made for homogeneous and crossedlamellar microstructures.

Although the homogeneous layer is mechanically inferior to the crossed lamellar layer, the combination of both may provide an efficient way of reducing vulnerability to durophagous predators. Studies investigating how cracks propagate from a weaker material into a stronger material have found that cracks are often efficiently stopped by the stronger material. Currey (1977) studied crack formation in the shell of the pearl oyster Pinctada margaritifera, which has a layer of nacre covered by a layer of weaker prismatic microstructure. He found that cracks travel by moving along the plates in the nacre, and rarely by breaking across them. He also noted that nacre hinders cracks originating in prisms, because the prismatic structure fractures at a low stress. This synergism between nacre and prismatic structures may be similar

(Menge 1978, Etter 1989), whelks produce thicker shells mostly by adding an homogeneous microstructure. In contrast, snails from wave-swept shores produce thinner shells reinforced with a proportionately thicker crossed-lamellar microstructure. Although the absolute thickness of the crossed-lamellar layer is the same between exposure regimes, proportionally the crossed-lamellar layer is thicker on exposed shores because shells are thinner.

Why is homogeneous microstructure disproportionately used to increase shell thickness? Growth rates of snails can be constrained by rates of calcification, and the greater the organic content the more energetically expensive and slower the growth (Palmer 1981, 1983, 1992). The simple structure and the low organic content of the homogeneous layer may make it an inexpensive material for thickening the shell and maximizing growth. In addition, it can be deposited quickly, providing a scaffold for the deposition of the more complex crossedlamellar layer. For example, trochids have shells made to that between crossed-lamellar and homogeneous structures. In fact, Currey \& Kohn (1976) suggest that a crossed-lamellar structure is better at hindering cracks than nacre because of the former's alternating lathe orientation.

Predation tends to be more intense on protected shores because predators are more abundant and efficient (Menge 1976, 1978, 1983). In response, Nucella lapillus produces much thicker shells on protected shores via both genetic and plastic mechanisms (Palmer 1990, Kirby et al. 1994, Trussell \& Nicklin 2002). Surprisingly, the weaker microstructure of the homogeneous layer is used disproportionately to increase thickness, rather than the stronger crossed lamellar microstructure. If shells are reinforced to reduce vulnerability to durophagous predators, why has natural selection favored the weaker homogeneous microstructure?

One possibility is that a fast growth rate to a size refuge may be an equally viable strategy for reducing 


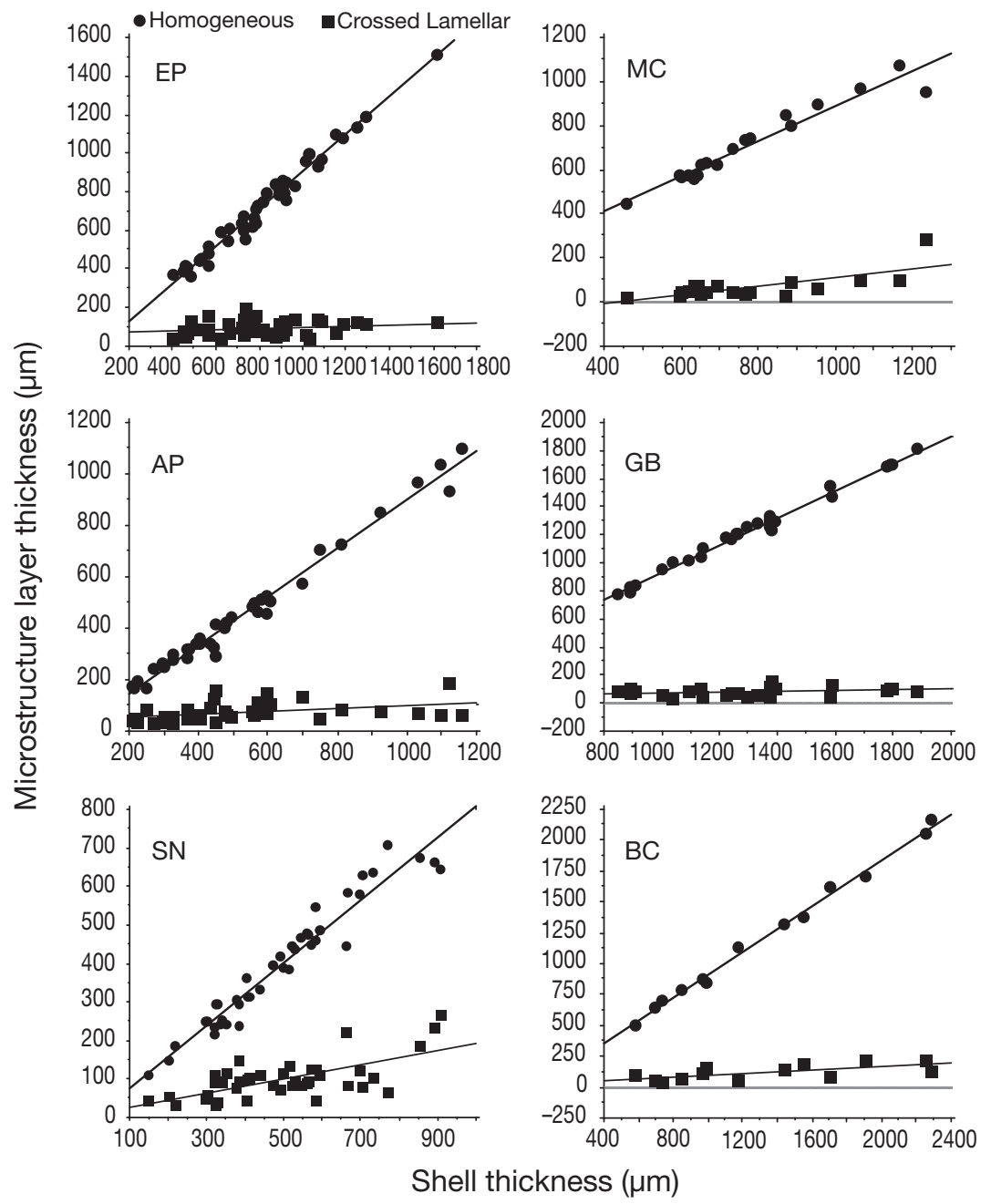

Fig. 4. Nucella lapillus. Least-squares regressions for thickness of each microstructural layer as a function of total shell thickness for each population. Site abbreviations as in Table 2

predation risk. Predation risk declines with increasing size, and once snails attain a sufficient size, they are not vulnerable to the typical guild of intertidal predators (Hughes \& Elner 1979, Currey \& Hughes 1982). Because food is widely available on sheltered shores and the low wave-energies minimize hydrodynamic constraints on foraging and maximum size (Menge 1978, Denny et al. 1985), snails can grow rapidly to attain a size refuge. Indeed, Nucella lapillus from protected shores grow more quickly and attain a larger size than conspecifics on wave-swept shores (Etter 1989, 1996). The homogeneous layer may be favored to maximize growth because, as noted above, growth rates can be constrained by rates of calcification (Palmer 1981, 1992), and the constraints are greater for microstructures with complex organic structures (Palmer 1983). The more complex geometrical construction of crossed-lamellar structures may make it less suitable for rapid shell growth because the deposition of the complex crystalline arrangement would take longer than a random arrangement (Currey 1977). The selective advantage of faster growth might outweigh the disadvantage of a weaker microstructure (Currey \& Taylor 1974), especially if snails can attain a size refuge from predation.

Another possibility might be constraints on altering the thickness of the crossed lamellar layer (West \& Cohen 1996). Increasing its thickness requires increasing the number of lathes, and this may be difficult structurally, biochemically or genetically. Because increasing shell thickness in response to predators appears to be an induced and graded response (Appleton \& Palmer 1988, Palmer 1990, Trussell \& Nicklin 2002), altering the thickness of the homogeneous layer may be more efficient and economical.

The use of the homogeneous layer to reinforce the shell involves an important tradeoff. Because the homogeneous layer is mechanically inferior to the crossed lamellar layer, a greater thickness is required to attain a given strength. The greater thickness reduces the internal volume of the shell (Vermeij \& Currey 1980, Currey \& Hughes 1982, Currey 1988, Trussell \& Etter 2001) which, in turn, constrains body size. For a given shell length, Nucella lapillus from sheltered shores have a smaller body mass than similar sized conspecifics from wave-swept shores (Etter 1989, Palmer 1990). Fecundity in muricids is typically correlated with body size (Feare 1970, Spight et al. 1974, Spight \& Emlen 1976, Etter 1989), so using the homogeneous layer to reinforce the shell may ultimately limit annual fecundity. Indeed, thin-shelled N. lapillus produce more offspring than thick-shelled conspecifics (Etter 1989, Geller 1990).

Interestingly, snails from exposed shores use a greater proportion of crossed-lamellar microstructure to build their shells. Since crab predators are rare and inefficient on wave-swept shores, the usefulness of the crossed-lamellar layer might be related to the tradeoff between shell thickness and internal volume (body size, fecundity). Food availability is greater on exposed shores (Etter 1989), but intense wave action reduces foraging time and efficiency, causing snails on exposed 

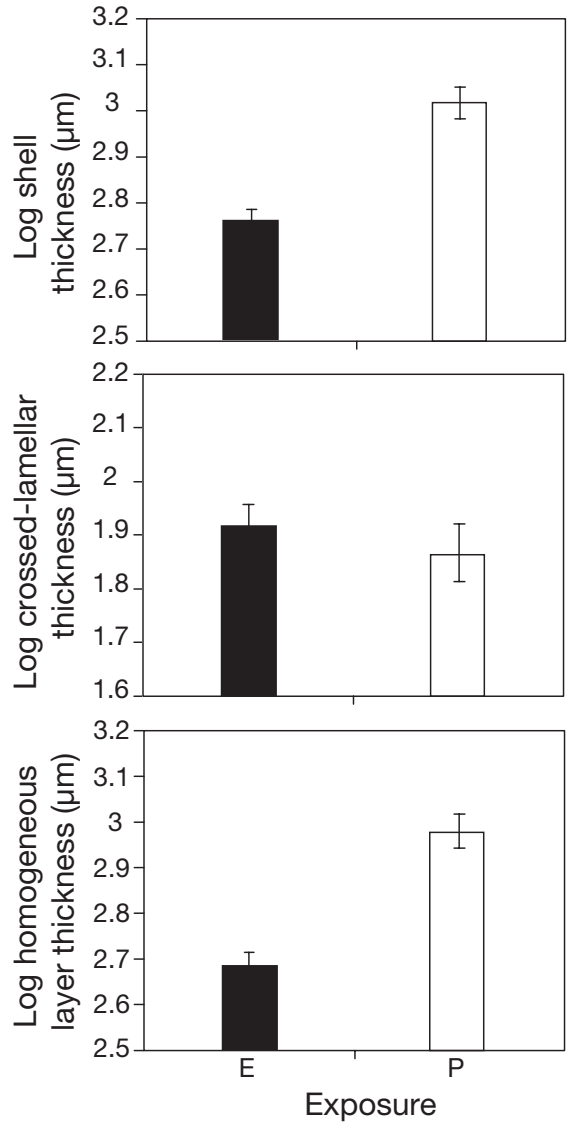

Fig. 5. Nucella lapillus. Least-squares adjusted means ( $\pm 1 \mathrm{SE})$ for shell thickness, crossed-lamellar layer thickness and homogeneous layer thickness for snails from different exposure regimes. E: exposed; P: protected. Covariate was shell length
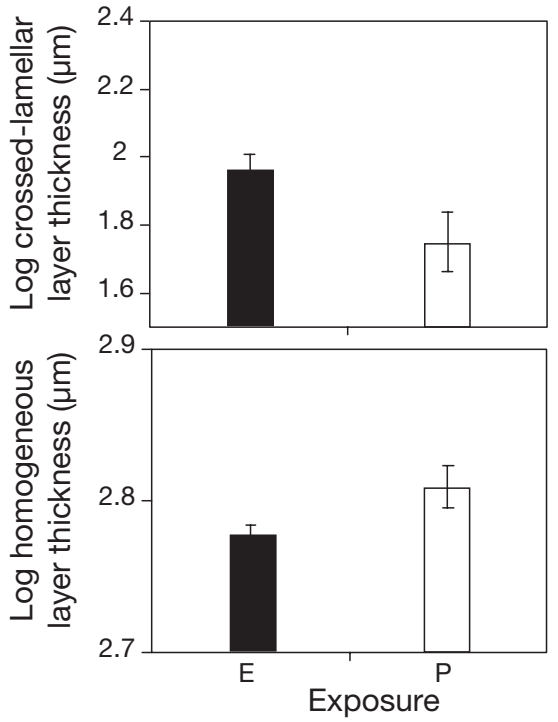

Fig. 6. Nucella lapillus. Least-squares adjusted means ( $\pm 1 \mathrm{SE})$ for crossed-lamellar layer thickness and homogeneous layer thickness for snails from different exposure regimes. E: exposed; P: protected. Covariate was shell thickness

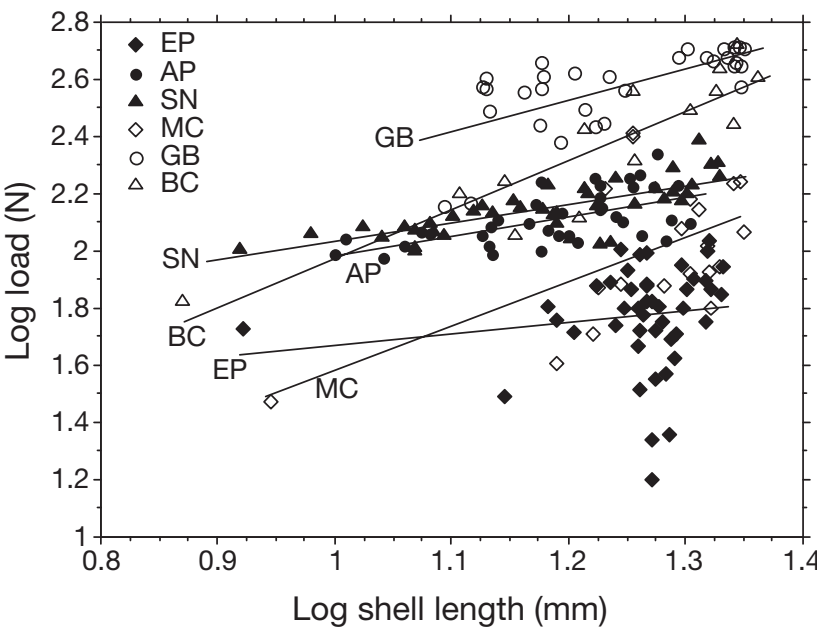

Fig. 7. Nucella lapillus. Load required to fracture shell as a function of shell length. Filled symbols: wave-exposed shores; open symbols: wave-protected shores. Full site names and regression lines are given in Table 2 . Note regression is not significant for EP, but line is included for comparison

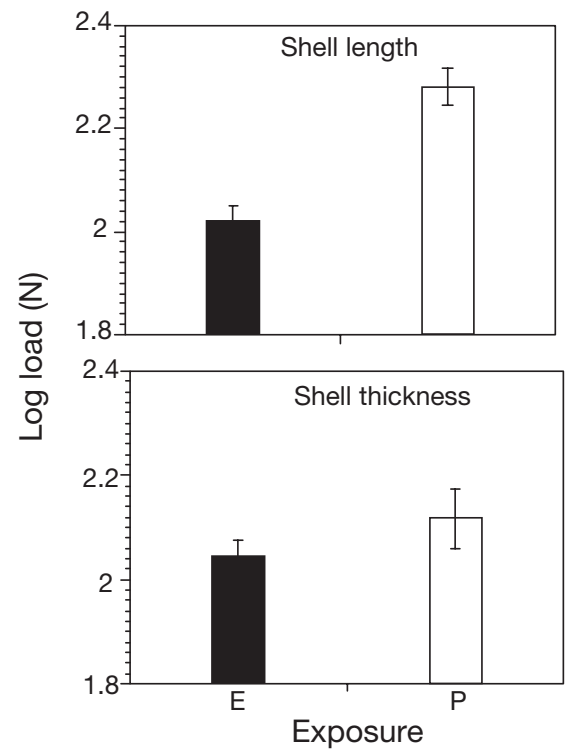

Fig. 8. Nucella lapillus. Least-squares adjusted mean ( $\pm 1 \mathrm{SE})$ shell loads for snails from different exposure regimes. E: exposed; P: protected. Covariate was either shell length or shell thickness

shores to grow more slowly (Menge 1978, Brown \& Quinn 1985, Etter 1989, 1996, Hughes \& Taylor 1997). Both slow growth and lack of predation reduce the viability of rapid growth to a size refuge. Moreover, intense wave action imposes hydrodynamic constraints on maximum size (Denny et al. 1985). On exposed shores, maximizing the internal volume of a shell may be critical for 2 reasons. First, higher mortality on wave-swept shores selects for higher fecundity (Etter 
1989) and thus for maximizing body size. Second, because snails on exposed shores produce a larger foot (Etter 1988a), a larger internal shell volume is needed to retract this entirely into the shell. Lack of predation, constraints on growth, the selective advantage of a larger body size and the need for a larger foot may all conspire to place a premium on maximizing internal volume of shells on wave-swept shores.

Of course, an adaptive explanation may not be necessary to account for the difference in microstructure proportionality between exposure regimes. When adjusted for shell length, the crossed-lamellar layer was similar in thickness between exposed and protected snails (Table 1, Fig. 5). The proportional difference obviously reflects the thinner homogeneous shell layer on exposed shores and thus may not be adaptive in nature. However, if energy is limited on exposed shores, as suggested by reduced growth (Menge 1978, Brown \& Quinn 1985, Etter 1989, 1996, Hughes \& Taylor 1997), it is puzzling that snails do not reduce the thickness of the more expensive microstructure.

One of the most surprising results to emerge from this work was that, at similar thickness, shells with a greater proportion of crossed-lamellar microstructure were weaker (Table 1, Fig. 8). Based on the mechanical properties of crossed-lamellar and homogeneous microstructures, the strength of a shell of a specific thickness should increase in direct proportion to the amount of crossed-lamellar microstructure. It is unclear why the shells of exposed-shore whelks were weaker, but this may be related to differences in shell shape between the exposure regimes. Shells of exposed-shore snails are typically wider, with larger apertures than shells of snails from sheltered shores (Crothers 1985). The wider aperture may have made the shells more vulnerable to the type of pressure applied during our experiments. However, this does not preclude the possibility that other factors may weaken shells. For instance, boring endosymbionts may weaken shells (Stefaniak et al. 2005), although typically they are more prevalent on protected shores.

Another explanation may be that it is difficult to accurately quantify small differences in shell strength arising from different proportions of microstructures while these are embedded within the shell. Material engineers typically isolate individual structures to estimate their biomechanical properties (Wainwright et al. 1976, Currey 1980). Without isolating specific microstructures, it is difficult to establish whether biomechanical properties of the shell are directly related to the thickness of specific layers. In our case, the weaker shells from the exposed shore snails (despite a thicker crossed-lamellar layer) may reflect differences in the strength of the homogeneous layer between snails from different exposure regimes. If the homogeneous layer produced by exposed snails is weaker than that produced by snails from protected shores, the thicker crossed lamellar microstructure may not offset this difference in strength. A more detailed analysis using uniform shell sections will be necessary to isolate the effects of specific microstructures.

Microstructure varies among snails from different exposure regimes and these variations influence the strength of the shell. Increased risk to durophagous predators favors the formation of a stronger/thicker shell, and this is accomplished in Nucella lapillus by disproportionately increasing the thickness of the homogeneous layer. The use of this weaker microstructure to reinforce the shell may reflect the importance of maximizing growth to reach a size refuge. For organisms that build shells comprised of different microstructures, natural selection will have to weigh the advantages of shell strength against its impact on growth rates, fecundity, and the energetic requirements of building and transporting the shell.

Acknowledgements. The scanning electron microscope work was conducted at the Museum of Science in Boston and the Imaging Laboratory at the University of New Hampshire. Shell sectioning was completed in the thin section laboratories at Harvard University and the University of New Hampshire. We thank D. Salvatore, N. Cherim, A. Abbin and W. Bothner for help in conducting the SEM work and shell sectioning. The apparatus used to fracture shells and measure load was provided by J. Ebersole. We thank A. R. Palmer for his helpful and insightful comments on a previous version of this manuscript. This research was funded by grants from the Western Society of Malacologists and NSF OCE-9811925.

\section{LITERATURE CITED}

Appleton RD, Palmer AR (1988) Water-borne stimuli released by crabs and damaged prey induce more predator-resistant shells in a marine gastropod. Proc Natl Acad Sci USA 85:4387-4391

Bandel K (1990) Shell structure of the Gastropoda excluding Archaeogastropoda. In: Carter GJ (ed) Skeletal biomineralization: Patterns, processes and evolutionary trends, Vol I. Van Nostrand Reinhold, New York, p 117-134

Bertness MD, Cunningham C (1981) Crab shell crushing predation and gastropod architectural defense. J Exp Mar Biol Ecol 50:213-230

Bertness MD, Garrity SD, Levings SC (1981) Predation pressure and gastropod foraging: a tropical-temperate comparison. Evolution 35:995-1007

Bøggild OB (1930) The shell structure of mollusks. K Dan Vidensk Selsk Skr 2:232-325

Boulding EG, Holst M, Pilon V (1999) Changes in selection on gastropod shell size and thickness with wave-exposure on northeastern Pacific shores. J Exp Mar Biol Ecol 232: 217-239

Brandwood A (1985) The effects of environment upon shell construction and strength in the rough periwinkle Littorina rudis Maton (Mollusca: Gastropoda). J Zool 206: 551-565

Brown KM, Quinn JF (1988) The effect of wave action on 
growth in three species of intertidal gastropods. Oecologia 75:420-425

Cook J, Gordon JE (1964) A mechanism for the control of crack propagation in all-brittle systems Proc R Soc Lond Ser A 282:508-520

Crothers JH (1985) Dog-whelks: an introduction to the biology of Nucella lapillus. Field Stud 6:291-360

Currey JD (1976) Further studies on the mechanical properties of mollusc shell material. J Zool 180:445-453

Currey JD (1977) Mechanical properties of mother of pearl in tension. Proc R Soc Lond Ser B 196:443-463

Currey JD (1980) Mechanical properties of mollusc shell. Symp Soc Exp Biol 34:75-97

Currey JD (1988) Shell form and strength. In: Trueman ER, Clarke MR (eds) The Mollusca, Vol 11. Form and function. Academic Press, New York, p 183-210

Currey JD, Hughes RN (1982) Strength of the dogwhelk Nucella lapillus and the winkle Littorina littorea from different habitats. J Anim Ecol 51:47-56

Currey JD, Kohn AJ (1976) Fracture in the crossed-lamellar structure of Conus shells. J Mater Sci 11:1615-1623

Currey JD, Taylor JD (1974) The mechanical behavior of some molluscan hard tissues. J Zool 173:395-406

Denny MW (1988) Biology and the mechanics of the waveswept environment Princeton University Press, Princeton, NJ

Denny MW (1999) Are there mechanical limits to size in wave-swept organisms? J Exp Biol 202:3463-3467

Denny MW, Daniel TL, Koehl MAR (1985) Mechanical limits to size in wave swept organisms. Ecol Monogr 55:69-102

Ebling FJ, Kitching JA, Muntz L, Taylor CM (1964) The ecology of lough Ine: experimental observations of the destruction of Mytilus edulis and Nucella lapillus. J Anim Ecol 33:73-83

Etter RJ (1988a) Asymmetrical developmental plasticity in an intertidal snail. Evolution 42:322-334

Etter RJ (1988b) Physiological stress and color polymorphism in the intertidal snail Nucella lapillus. Evolution 44:660-680

Etter RJ (1989) Life history variation in the intertidal snail Nucella lapillus across a wave exposure gradient. Ecology 70:1857-1876

Etter RJ (1996) The influence of wave action, prey type and foraging time on growth rates of the predatory whelk Nucella lapillus. J Exp Mar Biol Ecol 196:341-356

Feare CJ (1970) Aspects of the ecology of an exposed shore population of dogwhelks Nucella lapillus (L). Oecologia 5: $1-18$

Gabriel JM (1981) Differing resistance of various mollusc shell materials to simulated whelk attack. J Zool 194:363-369

Geller JB (1990) Consequences of a morphological defense: growth, repair and reproduction of thick and thin shelled morphs of Nucella emarginata (Deshayes) (Prosobranchia: Gastropoda). J Exp Mar Biol Ecol 144:173-184

Hughes RN, Elner RW (1979) Tactics of a predator, Carcinus maenas, and morphological responses of the prey, Nucella lapillus. J Anim Ecol 48:65-78

Hughes RN, Taylor MJ (1997) Genotype-environment interaction in the foraging behaviour of dogwhelks, Nucella lapillus (L.), under simulated environmental hazard. Proc R Soc Lond Ser B 264:417-422

Huitema BE (1980) The analysis of covariance and alternatives. Wiley \& Sons, New York

Jackson AP, Vincent JFV, Turner RM (1988) The mechanical design of nacre. Proc R Soc Lond Ser B 234:415-440

Jackson AP, Vincent JFV, Turner RM (1990) Comparison of nacre with other ceramic composites. J Mater Sci 25: $3173-3178$
Kamat S, Su X, Ballarini R, Heuer AH (2000) Structural basis for fracture toughness of the shell of the conch Strombus gigas. Nature 405:1036-1040

Kirby RR, Bayne BL, Berry RJ (1994) Phenotypic variation along a cline in allozyme and karyotype frequencies, and its relationship with habitat, in the dog-whelk Nucella lapillus, L. Biol J Linn Soc 53:255-275

Kitching JA, Muntz L, Ebling FJ (1966) The ecology of Lough Ine. XV. The ecological significance of shell and body forms in Nucella. J Anim Ecol 35:113-126

Kuhn-Spearing LT, Kessler H, Chateau E, Ballarini R, Spearing SM (1996) Fracture mechanisms of the Strombus gigas conch shell: implications for the design of brittle laminates. J Mater Sci 31:6583-6594

LaBarbera M (1989) Analyzing body size as a factor in ecology and evolution. Annu Rev Ecol Syst 20:90-117

Menge BA (1976) Organization of the New England rocky intertidal community: role of predation, competition and environmental heterogeneity. Ecol Monogr 46:355-393

Menge BA (1978) Predation intensity in a rocky intertidal community: effect of an algal canopy, wave action and desiccation on predator feeding rates. Oecologia 34:17-35

Menge BA (1983) Components of predation intensity in the low zone of the New England rocky intertidal region. Oecologia 58:141-155

Palmer AR (1979) Fish predation and the evolution of gastropod shell sculpture: experimental and geographical evidence. Evolution 33:697-713

Palmer AR (1981) Do carbonate skeletons limit the rate of body growth? Nature 292:150-152

Palmer AR (1983) Relative cost of producing skeletal organic matrix versus calcification: evidence from marine gastropods. Mar Biol 75:287-292

Palmer AR (1985) Adaptive value of shell variation in Thais lamellosa: effect of thick shells on vulnerability to and their preference by crabs. Veliger 27:349-356

Palmer AR (1990) Effect of crab effluent and scent of damaged conspecifics on feeding, growth, and shell morphology of the Atlantic dogwhelk Nucella lapillus (L). Hydrobiologia 193:155-182

Palmer AR (1992) Calcification in marine molluscs: How costly is it? Proc Natl Acad Sci USA 89:1379-1382

Palumbi SR (1984) Measuring intertidal wave forces. J Exp Mar Biol Ecol 81:171-179

Seeley RH (1986) Intense natural selection caused a rapid morphological transition in a living marine snail. Proc Natl Acad Sci USA 83:6897-6901

Spight TM, Emlen JM (1976) Clutch sizes of two marine snails with a changing food supply. Ecology 57:1162-1178

Spight TM, Birkeland C, Lyons A (1974) Life histories of large and small murexes (Prosobranchia: Muricidae). Mar Biol 24:229-242

Stefaniak LM, McAtee J, Shulman MJ (2005) The costs of being bored: effects of a clionid sponge on the gastropod Littorina littorea (L). J Exp Mar Biol Ecol 327:103-114

Taylor JD, Layman M (1972) The mechanical properties of bivalve (Mollusca) shell structures. Palaeontology 15:73- 87

Trussell GC (1996) Phenotypic plasticity in an intertidal snail: the role of a common crab predator. Evolution 50:448-454

Trussell GC, Etter RJ (2001) Integrating genetic and environmental forces that shape the evolution of geographic variation in a marine snail. Genetica 112:321-337

Trussell GC, Nicklin MO (2002) Inducible defenses in a marine snail: geographic variation in sensitivity to risk cues and the scaling of trade-offs. Ecology 83:1635-1647

Trussell GC, Johnson AS, Rudolph SG, Gilfillan ES (1993) Resistance to dislodgment: habitat and size-specific differ- 
ences in morphology and tenacity in an intertidal snail Mar Ecol Prog Ser 100:135-144

Vermeij GJ (1978) Biogeography and adaptation: patterns of marine life. Harvard University Press, Cambridge, MA

Vermeij GJ (1982) Phenotypic evolution in a poorly dispersing snail after arrival of a predator. Nature 299:349-350

Vermeij GJ, Currey JD (1980) Geographical variation in the strength of thaidid snail shells. Biol Bull (Woods Hole) 158: 383-389

Wainwright WD Biggs SA, Currey JD, Gosline JM (1976) Mechanical design in organisms. Princeton University

Editorial responsibility: Roger N. Hughes (Contributing

Editor), Bangor, UK
Press, Princeton, NJ

Watabe N (1988) Shell structure. In: Trueman ER, Clarke MR (eds) The Mollusca, Vol 11. Form and function. Academic Press, New York, p 69-104

West K, Cohen A (1996) Shell microstructure of gastropods from Lake Tanganyika, Africa: adaptation, convergent evolution, and escalation. Evolution 50:672-681

West K, Cohen A, Baron M (1991) Morphology and behavior of crabs and gastropods from Lake Tanganyika, Africa: implications for lacustrine predator-prey coevolution. Evolution 45:589-607

Submitted: November 18, 2005; Accepted: February 28, 2006 Proofs received from author(s): September 18, 2006 